\title{
LESÕES ISQUÊMICAS DO TESTÍCULO DE CÃES MEDIANTE GARROTEAMENTO TEMPORÁRIO DO CORDÃO ESPERMÁTICO
}

\author{
ISCHEMIC LESIONS OF THE DOG'S TESTICLE CAUSED BY GARROTING \\ THE SPERMATIC CORD
}

\author{
Affonso Luiz Ferreira ${ }^{1}$ Ana Rosa Crisci ${ }^{2}$ Segundo Amarillis Salize Fiorani ${ }^{3}$ José Luiz Laus $^{4}$ \\ Adriana Torrecilhas Jorge
}

RESUMO

No homem, considera-se emergência urológica a isquemia decorrente de torção testicular. Há controvérsias quanto ao tempo necessário para causar morbidade ou reversibilidade das lesões isquêmicas das células germinativas. Este estudo realizado em cães tem como objetivo determinar o período crítico do aparecimento e a reversibilidade das lesões após garroteamento do cordão espermático. Os resultados mostraram que duas horas é o período crítico de sobrevivência das células germinativas à isquemia. Após 60 dias, houve recuperação completa do epitélio germinativo. Animais com período de isquemia de $2 \mathrm{~h}$ 30 min, examinados após 60 dias, apresentaram necrose testicular.

Palavras-chave: cão, testículo, isquemia.

SUMMARY

Ischemia due to testicular torsion is considered to be an urologic emergency in men. There is controversy about the time necessary to cause morbidity or reversibility of the ischemic lesions of germ cells. The objective of the present study conducted on dogs was to determine the critical time of onset and the reversibility of the lesions after garroting the spermatic cord. The results showed that 2 hours is the critical period of ischemia survival in germ cells. After 60 days there was full recovery of the germinal epithelium. Animals with periods of ischemia of $2 \mathrm{~h}$ and 30 min presented testicular necrosis when examined 60 days later.

Key words: dog, testicle, ischemia.

\section{INTRODUÇÃO}

A isquemia decorrente da torção testicular no homem é uma emergência urológica, de incidên- cia não muito rara em indivíduos jovens (WILLIAMSON, 1976). É consenso geral que o sucesso da intervenção em tais ocorrências vai depender do tempo de isquemia. Existem, no entanto, numerosas dúvidas e controvérsias sobre o tempo crítico de isquemia, quanto à morbidade ou reversibilidade das lesões isquêmicas das células germinativas.

A isquemia testicular que se instala no homem é conseqüente à torção testicular, e NOSKED et al. (1998), em uma retrospectiva histórica sobre torção de órgãos escrotais, considera essa ocorrência como emergência urológica, embora a taxa de sobrevivência dos testículos seja extremamente baixa. HAYNES et al. (1983) dizem que a taxa de recuperação corresponde ao intervalo decorrido entre o início dos sintomas e a intervenção.

Com vistas ao estudo da reprodução das lesões isquêmicas no testículo e da determinação do período crítico compatível com a reversibilidade das lesões, numerosos trabalhos experimentais foram realizados em diferentes espécies animais.

Assim, MAATZ (1934) considerou que lesões testiculares no rato ocorriam após 8 horas de isquemia. HARRISON \& OETTLÉ (1950) descrevem o aparecimento de discretas alterações na espermatogênese de ratos após 20 minutos de isquemia e que, decorrido uma hora, havia degeneração das

\footnotetext{
${ }^{1}$ Médico, Professor Doutor Titular da Universidade de São Paulo (USP), Ribeirão Preto, SP.

${ }^{2}$ Docente do Centro Universitário Barão de Mauá- Ribeirão Preto- SP.

${ }^{3}$ Médico, Professor Doutor Docente da Faculdade de Medicina de Catanduva, Catanduva, SP.

${ }^{4}$ Médico Veterinário, Professor Adjunto do Departamento de Clínica e Cirurgia Veterinária, FCAV/UNESP, Rodovia Carlos Tonnani

Km 5, 14870-000, Jaboticabal/SP. E-mail: Jllaus@ fcav.unesp.br Autor para correspondência.

${ }^{5}$ Médico Veterinário, Pós-graduando em Cirurgia Veterinária, FCAV/ UNESP, Campus de Jaboticabal.

Recebido para publicacão em 02.06.99. Aprovado em 15.12.99
} 
células germinativas. STEINBERGER \& TJIOE (1969) admitem duas horas como o tempo de isquemia suficiente para provocar a destruição das células germinativas do rato, porém, com preservação das espermatogonias. No cão, SMITH (1955) considera 4 horas como o período crítico de isquemia.

$\mathrm{O}$ presente experimento objetivou esclarecer a discrepância dos resultados referentes ao tempo crítico de isquemia, mediante o garroteamento do cordão espermático do cão, a intervalos de tempos crescentes; foram determinadas as lesões e a reversibilidade das mesmas.

\section{MATERIAL E MÉTODOS}

Foram utilizados 38 cães sem raça definida, machos, fornecidos pelo Biotério Central da Faculdade de Medicina de Ribeirão Preto-USP. Os animais foram separados em dois grupos. O grupo I, com 27 animais, foi reservado para a determinação do tempo crítico de isquemia.

Mediante garroteamento do cordão espermático, sob anestesia, em tempos crescentes de 30 minutos até 4 horas, procurou-se estabelecer o período de tempo de garroteamento no qual as lesões das células germinativas, avaliadas 6 dias após, mostravam-se invariavelmente repetitivas e evoluíam para necrose testicular. Estabelecido esse período como crítico, três animais foram submetidos a garroteamento a cada 15 minutos, a fim de caracterizar com maior precisão o aparecimento das lesões isquêmicas, em relação ao tempo.

O grupo II constou de oito animais submetidos aos tempos de isquemia, considerados como críticos, com base nas avaliações prévias das lesões testiculares encontradas nos animais do grupo 1. A avaliação das lesões, nesse grupo, foi realizada 60 dias após o garroteamento do cordão espermático e serviu para caracterizar a reversibilidade em função do tempo crítico de garroteamento.

Realizou-se uma incisão de $3 \mathrm{~cm}$ de comprimento a partir do anel inguinal superficial, sempre na região inguinal direita, compreendendo o tegumento e a fascia de inserção do músculo oblíquo externo. O cordão espermático foi exposto através da incisão e, após dissecção cuidadosa, enlaçado por uma sonda de Nelaton $\mathrm{n}^{\mathrm{o}} 8$, presa com uma pinça de Kocker (SMITH, 1955).

A sonda promovia assim o garroteamento dos vasos do cordão espermático, com o mínimo de traumatismo dos mesmos. A sutura foi realizada por pontos separados com fio de algodão, deixando-se a pinça e parte da sonda exteriorizadas através de um pequeno hiato da incisão (Figura 1). Decorridos os tempos de isquemia convencionados, soltou-se a pinça e retirou-se suavemente a sonda, desenlaçando-se o cordão, sem necessidade de posteriores tratamentos no local, a não ser uma assepsia.

Decorridos 6 dias após os tempos de garroteamento nos animais do grupo 1 e 60 dias para os animais do grupo 11, fez-se uma reoperação, sob anestesia geral, para a retirada dos testículos através de incisões escrotais. Os testículos contralaterais foram retirados e avaliados histologicamente.

Logo após a retirada dos testículos, fez-se piques com tesoura na albugínea junto aos pólos dos testículos para melhor penetração do fixador e, a seguir, foram colocados, durante 24 horas, na solução fixadora de Bouin. Decorrido o período de fixação, os fragmentos selecionados foram clivados e submetidos aos métodos rotineiros para inclusão em parafina. Nos exames à microscopia de luz, utilizaram-se cortes de $6 \mu \mathrm{m}$ de espessura e estes, corados com hemalúmem eosina ( $\mathrm{H} \mathrm{E}$ ). Alguns cortes foram corados com o tricrômico de Masson e outros submetidos à reação do Ácido Periódico e reativo de Schiff (PAS) e hemalúmem de Ehrlich.

Os tempos de garroteamento de $1 \mathrm{~h}$; 1h30min; 2h e $2 \mathrm{~h} 30 \mathrm{~min}$ foram realizados em um maior número de animais, por corresponderem aos tempos nos quais as lesões isquêmicas foram bastante acentuadas. A repetição teve por finalidade configurar as lesões que, após 6 dias, evoluíram para necrose ou atrofia testicular. Nesses mesmos grupos estiveram incluídos aqueles animais cuja avaliação foi feita 60 dias após, para configurar-se a reversibilidade das lesões.

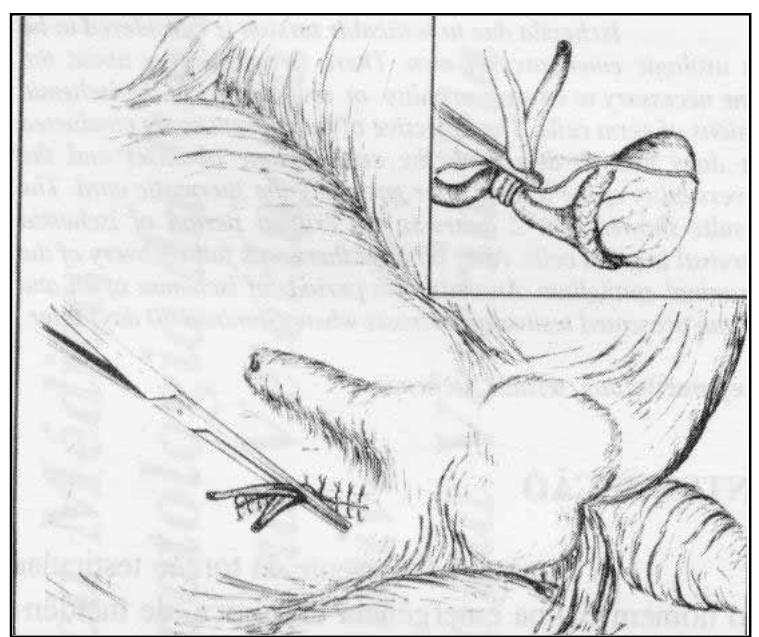

Figura 1 - Esquema ilustrativo da clampagem do cordão espermático, com parte da sonda e pinça exteriorizadas. No detalhe, o aspecto da clampagem dos elementos constituintes do cordão espermático. 


\section{RESULTADOS}

Como fora convencionado, os animais do Grupo 1 (27 animais), submetidos a diferentes períodos de garroteamento do cordão, foram todos avaliados seis dias após os garroteamentos. Foi constatado que após 30 minutos e uma hora de garroteamento não houve danos no epitélio germinativo, ocorrendo espermatogênese normal, com túbulos íntegros e formação de espematozóides jovens e maduros (Figura 2).

Após o garroteamento de duas horas, houve ausência da espermiogênese com formação de conglomerados de espermátides jovens degenerados, existindo, porém, algumas gerações de espermatócitos e espermatogonias ainda preservadas (Figura 3, fotomicrografias 3 e 4). Havia degeneração quase completa das células germinativas, restando apenas algumas espermatogônias (3). As fotomicrografias 5 e 6 correspondem, respectivamente, o garroteamento do cordão espermático por 3 e 4 horas. Os aspectos exibidos nas fotomicrografias foram o de degeneração tubular com desorganização do epitélio germinativo das gerações celulares e túbulos exibindo necrose. Havia, porém, uma aparente evidenciação das células intersticiais e infiltrado celular intertubular (Fotomicrografia 6).

No período de garroteamento de $2 \mathrm{~h} 30 \mathrm{~min}$, as lesões das células germinativas foram semelhantes, embora se tratasse de dois animais diferentes. A espermatogênese estava inteiramente abolida, as espermátides jovens aglomeradas exibiram graus variados de degeneração. Algumas gerações celulares de espermatócitos estavam preservadas e havia preservação das espermatogônias (Figura 4, fotomo-

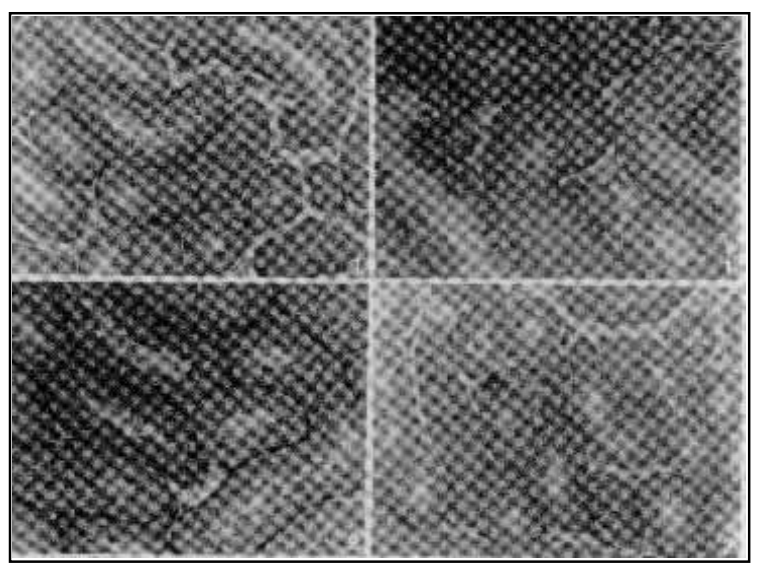

Figura 2 - As fotomicrografias representam respectivamente $(1 \mathrm{e}$ 2) testículos de cães submetidos a 30 minutos e uma hora de garroteamento. Pode-se notar espermatogênese ativa normal (HE-e PAS.-164X).

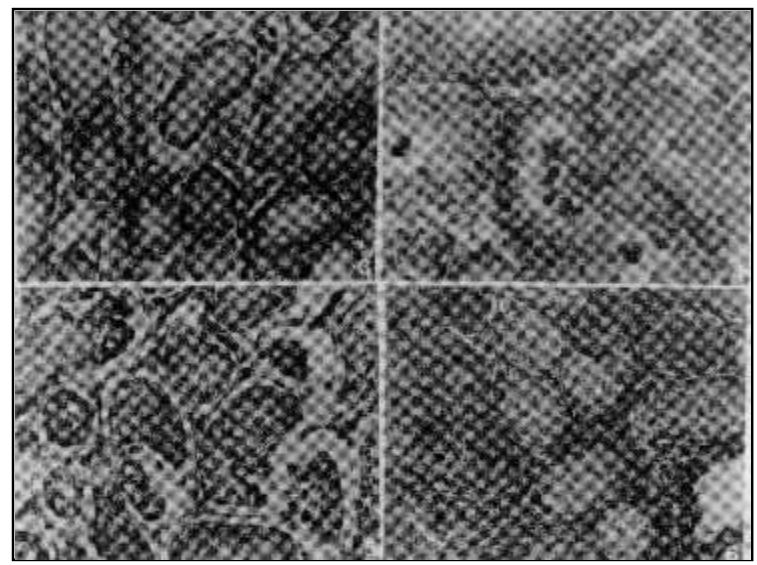

Figura 3 - As fotomicrografias 3 e 4 correspondem às lesões testiculares decorrentes de duas horas de clampagem. As fotomicrografias 5 e 6 são lesões decorrentes de 3 e 4 horas de clampagem do cordão espermático.

crografia 7, 8). Observou-se edema intersticial e se repetia o aspecto de hipertrofia aparente das células intersticiais (7).

A avaliação dos testículos 60 dias após a garroteamento dos cordões espermáticos é observado na figura 5. Os túbulos seminíferos apresentamse normais com espermatogênese ativa de testículo cujo cordão foi submetido a uma hora de garroteamento (fotomicrografia 9). Durante duas horas de garroteamento do cordão espermático, os túbulos seminíferos permanecem preservados e a espermatogênese ativa (10). Ocorreram degeneração e atrofia testicular com 2h 30min (fotomicrografias 11 e 11').

O epidídimo sofreu isquemia durante duas horas, mas houve a preservação do epitélio e presença de estereocílios (Figura 6, fotomicrografia 12). No entanto, quando submetido a três horas de isquemia, houve hipertrofia do epitélio do ducto do epidídimo e o desaparecimento de estereocílios (13).

\section{DISCUSSÃO}

O tempo de isquemia é fator crítico para a recuperação das células germinativas. As experiências conduzidas em animais de espécies diferentes e, especificamente no rato, não devem reproduzir as eventuais lesões decorrentes da torção testicular no homem. O canal inguinal no rato tem continuidade com a cavidade abdominal, e o testículo é impedido de retornar à cavidade abdominal apenas em função da existência de um tampão de gordura supra-epidimário.

PALMER et al. (1997), estudando comparativamente o grau de insuficiência vascular, mediante o emprego de um Doppler fluorômetro a laser em ratos cujos cordões foram submetidos ora a tor- 


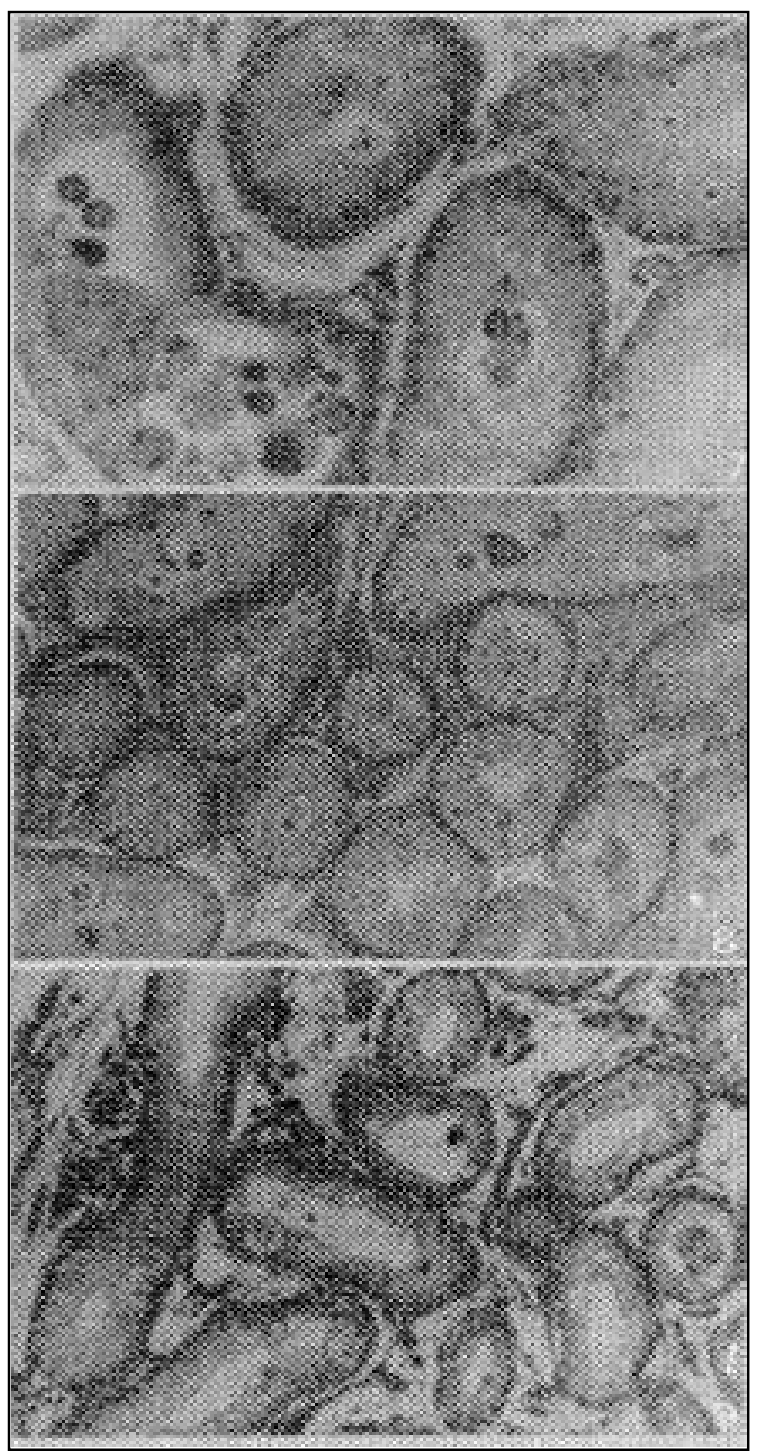

Figura 4 - Fotomicrografias de testículos submetidos à clampagens do cordão espermático por 2:00h e 15 e 2:00h e 30, fotomicrografias 7, 8 e9. (HE 164X)

ções, ora a clampagens, concluíram que a isquemia decorrente da clampagem é mais severa e reprodutível, que a induzida pela torção de $720^{\circ}$, freqüentemente utilizada.

No cão, SMITH (1955) considerou 4 horas como tempo crítico que levaria à lesão total do epitélio germinativo. No homem, esses períodos variariam entre 5 e 10 horas (SEKOGLUND et al., 1970). Para o rato, há referências tão discrepantes quanto ao período crítico, que vão desde uma hora (HARRISON \& OETTLÉ, 1950) até 8 horas (MAATZ, 1934).

As primeiras alterações testiculares encontradas nesta pesquisa, empregando o garrotea-

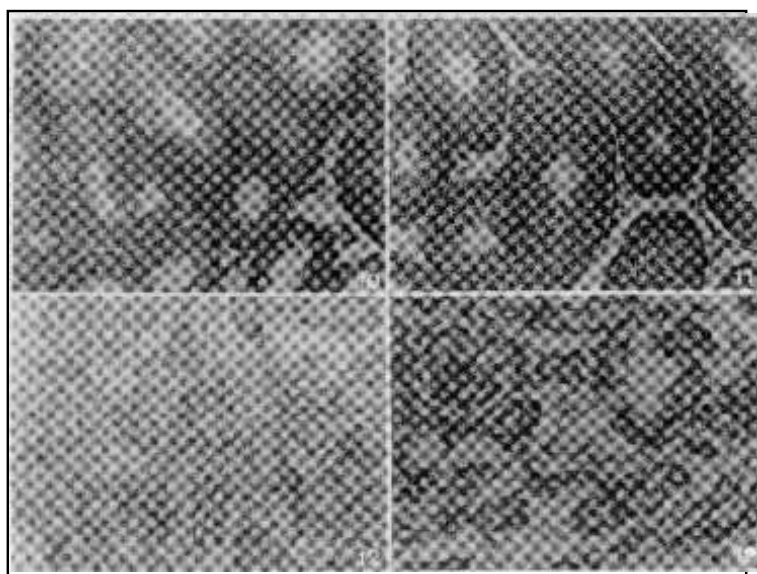

Figura 5 - Fotomicrografias de testículos observados 60 dias após a clampagem do cordão espermático por $1 \mathrm{~h}$ e $2 \mathrm{~h}$ (11). As fotomicrografias 12 e 12 ' são representativas da atrofia e necrose após $2 \mathrm{~h} 30 \mathrm{~min}$ de isquemia por clampagem do cordão, após 60 dias. (HE 164X)

mento do cordão para a produção da isquemia, ocorreram 1h30min após, e se caracterizavam ora apenas pela ausência da espermiogênese, ora com a supressão de várias gerações de espermatócitos 1 e com secções de túbulos seminíferos exibindo apenas células de Sertoli e espermatogônias.

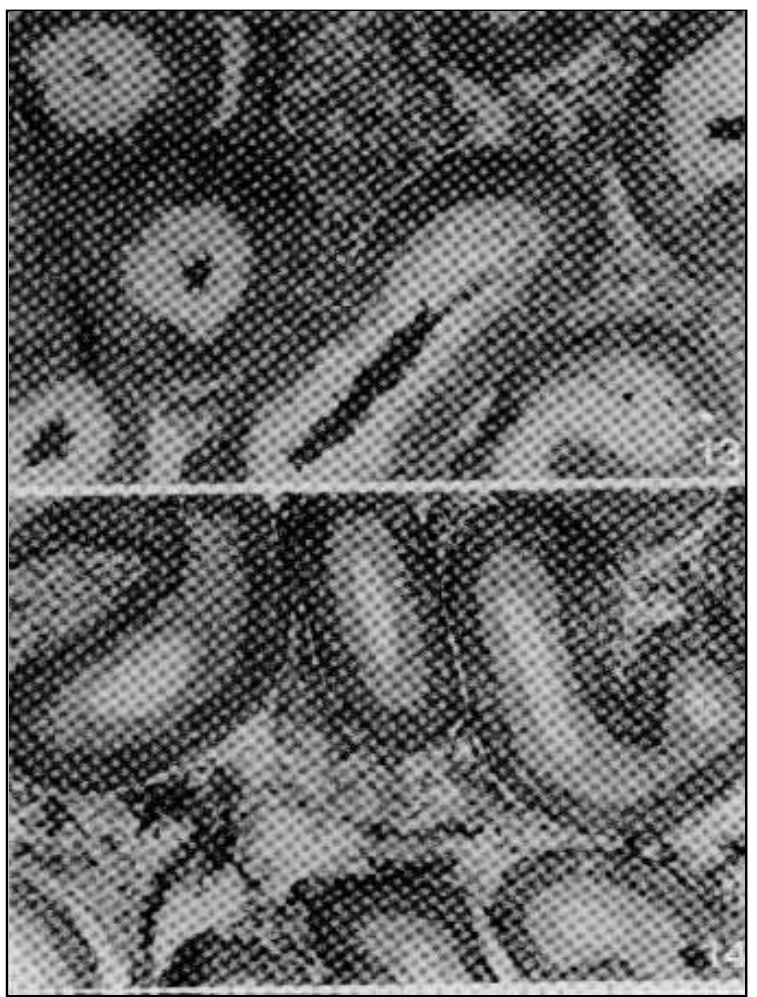

Figura 6 - Fotomicrografia de epidídimos após 2h (16) e 3h (17) de clampagem do cordão espermático. (HE 164X) 
HARRISON \& OETTLÉ (1950) consideram a lesão decorrente da isquemia como sendo inespecífica e traduzida pela parada da espermiogênese e conglomerado de espermátides em vias de degeneração decorrentes da anóxia.

A partir de duas horas de isquemia, as lesões das células germinativas eram constantes em todos os casos e se caracterizavam por parada da espermiogênese, degeneração de espermátides e de espermatócitos 1 até estadio de paquíteno. Em alguns animais, após duas horas, acrescentavam-se lesões como necrose tubular e hialinização da membrana tubular. Para SMITH (1955), nesse tempo de isquemia ocorria apenas uma pequena diminuição da espermatogênese.

A frequiência e a característica das lesões observadas permitiram admitir duas horas, como sendo o período crítico de isquemia para o testículo de cão. Isquemia acima de duas horas e trinta minutos, e avaliada 6 dias após, promoveu atrofia tubular geral e necrose tubular. Paradoxalmente, o tecido intersticial manteve-se por mais tempo íntegro além do período de até duas horas de isquemia, possivelmente por não estar isolado pela membrana tubular. $\mathrm{O}$ epidídimo mostrou-se mais resistente e apenas após quatro horas de isquemia, o epitélio não exibia esteriocílios e o espaço entre os cortes do ducto do epidídimo apresentava infiltrado celular e edema intersticial. Ficaram estabelecidas duas horas como o período crítico de sobrevivência das células germinativas à isquemia.

Animais submetidos a isquemias de uma e duas horas e examinados após 60 dias mostraram a recuperação completa do epitélio germinativo. Animais com isquemia de $2 \mathrm{~h} 30 \mathrm{~min}$, examinados após 60 dias, exibiram necrose testicular.

Não obstante os dados aqui discutidos, faz-se mister atentar para um fator importante, que seria aquele relacionado ao ciclo espermatogenético dos diferentes animais. Segundo FOOTE $\boldsymbol{e t}$ al. (1972), o ciclo espermatogenético do cão correspon- de a 13,6 dias. Portanto, avaliações realizadas após os períodos de isquemia não informam senão as lesões imediatas decorrentes da anóxia. Nesta pesquisa, as avaliações foram realizadas 6 dias após o tempo de isquemia e 60 dias após o estabelecimento de um tempo crítico de isquemia. É surpreendente que 30 minutos além de duas horas de isquemia é tempo suficiente para culminar em atrofia e necrose de todo o epitélio germinativo.

\section{REFERÊNCIAS BIBLIOGRÁFICAS}

FOOTE, R.H, SWIERSTRA, E.E., HUNT, W. L. Spermatogenesis in the dog. Anat Rec, v.173, p.341-348, 1972.

HARRISON, R.G., OETTLÉ, A.G. Pathologic changes in the rat testis following ischaemia. Society for the study of fertility and sterility, v.32, p.6-11, 1950.

HAYNES, B.E., BESSEN, H.A.; HAYNES,V.E. The diagnosis of testicular torsion. J Am Med Assoc, v.249, n.18, p.2522$2527,1983$.

MAATZ, R. Anatomic changes following temporary circulatory strangulation of the testis. Centralbl F allg Path u Path Anat, v.59, p.243, 1934.

NOSKED, H.D., KRAUS,S.W., ALTINKILIC, B.M., $\boldsymbol{e} \boldsymbol{t} \boldsymbol{a l}$. Historical milestones regarding torsion of the scrotal organs. J Urol, v.159, n.1, p.13-16, Jan, 1998.

PALMER, J.S., CROMIE, W. J., PLZK, L.F., et al. . A platelet activating factor antagonist attenuates the effects of testicular ischemia. J Urol, v.158, n.3, pte 2, p.1186-1190, 1997.

SEKOGLUND, R.W., MCROBERTS, J.W., RADGE, H. Torsion of the spermatic cord. A review of the literature and analysis of 70 cases. J Urol, v.104, p.604-611, 1970.

SMITH, G. I. Celular changes from graded testicular ischemia. J Urol, v.73, p.355-362, 1955.

STEINBERGER, E., TJIOE, D. Spermatogenesis in rat testes after experimental ischemia. Fertility and Sterility, v.20, p.39-649, 1969 .

WILLIAMSON, R.C. Torsion of the testis and alliedconditions. Br J Surg, v.63, n.6, p.465-476, 1976. 